\title{
Optimal Weight Gain During Pregnancy in Japanese Women: Is It Okay?
}

\author{
Shunji Suzuki
}

\section{To the Editor}

In this journal, recently we have investigated some reports concerning the optimal gestational weight gain (GWG) in the healthy Japanese women with favorable perinatal outcomes of singleton pregnancy [1-3]. In our reports [2], for example, the average GWG in the normal-weight (body mass index (BMI) during pre-pregnancy, $\mathrm{kg} / \mathrm{m}^{2}$ : 18.5 - 24.9) women with the favorable perinatal outcomes was suggested to be $11.4 \mathrm{~kg}$ in the consecutive deliveries at Japanese Red Cross Katsushika Maternity Hospital in the Tokyo downtown; however, Nomura et al [4] reported in another journal that the average GWG for the favorable outcomes seemed to be $10.2 \mathrm{~kg}$ ( $\mathrm{P}<0.05$ by the Student's $t$-test) for the normal-weight women in the consecutive deliveries at Japanese Red Cross Medical Center in the central Tokyo (Fig. 1).

Based on the reports [1-4], there were some differences in some clinical backgrounds between the pregnant women living in the two areas of Tokyo. The rate of underweight (BMI < 18.5) women during pre-pregnancy in the central Tokyo was higher significantly than that in the Tokyo downtown $\left(25.6 \%\right.$ vs. $9.6 \%, \mathrm{P}<0.05$ by the $\mathrm{X}^{2}$ test), although there was no significant difference in the rate of normal women between the two areas $(82.1 \%$ vs. $77.7 \%)$. Both rates of underweight women in the two areas are different significantly from the average rate in the same-aged women in Japan (vs. about 20\%, $\mathrm{P}<0.05)$.

The annual income per household in the central Tokyo is about 7 million Japanese yen $(=\$ 63,000)$, which has been reported to be about two times that of Tokyo downtown (about 3.3 million Japanese yen) $[5,6]$. We believe that Japan is not a poor country; however, the existence of health inequality based on the difference of rich and poor has been becoming a serious problem in Japan $[5,6]$. In the market survey in Tokyo downtown, more frequent sales of carbohydrate-based pre-packaged foods and lower sales of vegetables have been pointed out compared to the center of Tokyo. These have been also suggested to be related to the differences in healthy life span in Tokyo, Japan $[5,6]$.

To lead to the favorable perinatal outcomes, we had been exploring the optimal GWG of Japanese women; however, what really matters may not be indicated by the range of body weight only.

\section{References}

1. Suzuki S. Optimal weight gain during pregnancy in Japanese women. J Clin Med Res. 2016;8(11):787-792.

2. Suzuki S. Gestational weight gain in Japanese women with favorable perinatal outcomes. J Clin Med Res. 2017;9(1):64-66.

3. Suzuki S. Optimal pre-pregnancy body mass index cutoffs for obesity in Japan. J Clin Med Res. 2017;9(2):180181.

4. Nomura K, Kido M, Tanabe A, Nagashima K, Takenoshita S, Ando K. Investigation of optimal weight gain during pregnancy for Japanese Women. Sci Rep. 2017;7(1):2569.

5. Ikeda T. Mainichi Forum: For the future of Japan (in Japanese).https://mainichi.jp/articles/20160509/org/00m/010/ 042000c (December 31, 2017).

6. The Asahi Shimbun: Income differentials (in Japanese). http://www.asahi.com/topics/word (December 31, 2017).

Manuscript submitted December 31, 2017, accepted January 16, 2018

Department of Obstetrics and Gynecology, Japanese Red Cross Katsushika Maternity Hospital, 5-11-12 Tateishi, Katsushika-ku, Tokyo 124-0012, Japan. Email: czg83542@mopera.ne.jp 


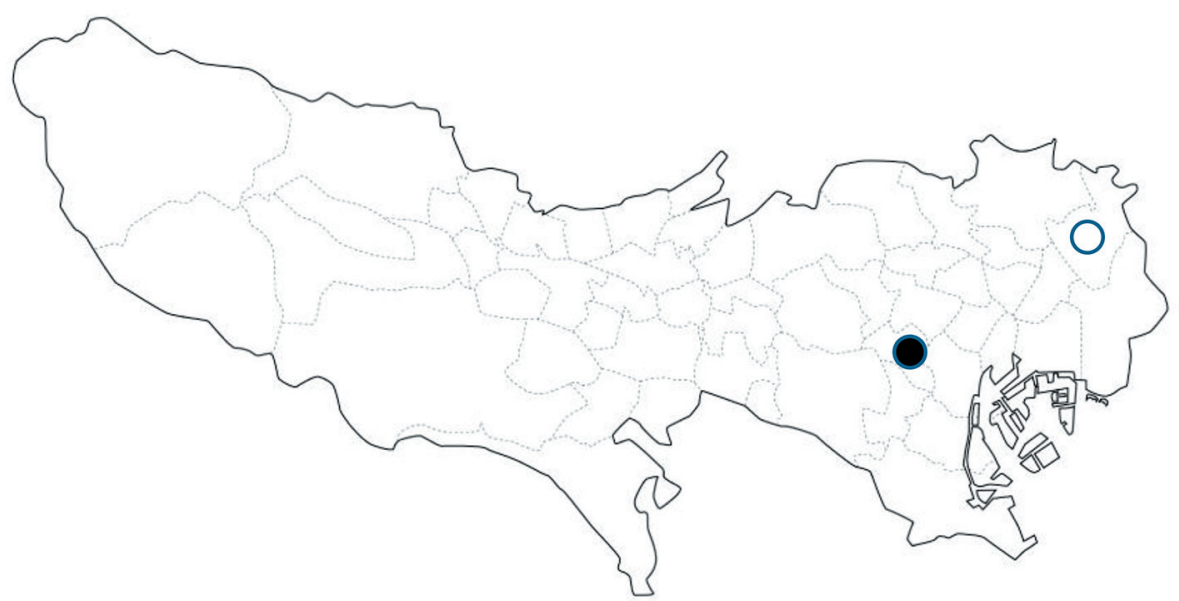

Figure 1. Map of Tokyo, Japan showing the places of Japanese Red Cross Katsushika Maternity Hospital (open circle) and Japanese Red Cross Medical Center (closed circle). 